\title{
Analysis of Coffee-Based Cropping Systems in Upland Cavite, Philippines Toward Improved Sustainability
}

\author{
Gilchor P. Cubillo \\ Cavite State University, Cavite, Philippines
}

\begin{abstract}
The study was conducted to: (1) identify the factors which serve as opportunities to the coffee-based cropping systems that will contribute to the productivity, profitability, and sustainability of the systems; (2) identify external factors which serve as threats to the systems; (3) determine if there exist significant differences in the levels of systems sustainability across the three types of cropping patterns; and (4) recommend improved cropping systems appropriate in upland Cavite that will provide the farmers with higher production efficiency, better profitability, and sustainable systems. The perceptions of the experts were consistent with the results of analysis using the farm level data gathered from the coffee-based farmers. Results of the analysis showed that in all the cropping patterns (municipalities), the economic dimension registered the highest sustainability index implying that farmers consider the economic variables as the major contributors to the sustainability of their farms. Silang farms registered to have the highest sustainability index for economic dimension. Cropping pattern 3 (intercropping coffee with industrial and commercial crops) would appear to be the best cropping system and worth recommending to interested farmers since intercropping coffee with industrial or commercial crops generated more income for the farmers and these intercrops produced the highest value per unit of resource or input used to produce them.
\end{abstract}

Keywords: multiple cropping, coffee-based cropping systems, systems dimensions, systems sustainability

Most crop production programs in the Philippines have been patterned after the traditional single-commodity approach where the concentration is on increasing the production of a particular commodity. However, recent developments forced the government to endeavour in multiple-commodity programs for obvious reasons that from the standpoint of the national economy, the multiple system of farming can contribute to economic development through increased total production per unit of land, increased employment on the farm, increased rural family income, and a more egalitarian distribution of income.

Another benefit that could spring out of the multiple-cropping system is the diversity of food crops that can be made available to farm families and urban consumers. Aside from these reasons, a multiple-cropping systems approach was introduced and promoted by the government because the overall efficiency of single-commodity approach of government programs tends to decrease over the years since various crops could already be covered by one program, to reduce government expenditure. Multiple cropping (Arizala \& Gonsalves, 1990) or the practice of growing several crops on the same piece of land in a year, is an ancient strategy for crop production among farmers in the Philippines and other countries in the tropics. Traditionally,

Corresponding author: Gilchor P. Cubillo, Ph.D., associate professor, Department of Economics, Cavite State University, Cavite, Philippines; research fields: agricultural economics, business management, and entrepreneurship. 
it is used by subsistence farmers primarily to increase the diversity of their products and the stability of their annual output.

\section{The Coffee-Based Cropping Systems}

In order to strengthen the agriculture sector in the Philippines, crop diversification was identified by the national government as a strategy in the Medium-Term Philippine Development Plan, 1987-1992 (Adriano \& Cabezon, 1993). The strategy was implemented to support food security, greater employment opportunities, increased farm income, and reduced dependence on traditional export commodities which are facing declining demand in the world market. One of the components of this strategy was the promotion of the multiple cropping technique of farming. Multiple cropping may take different cropping patterns and component technologies. Some of the most common methods of multiple cropping are sequential cropping, inter-cropping, and relay cropping.

The province of Cavite is one of the leading upland multiple cropping areas in the country. This is evidenced by the wide agricultural areas devoted to multiple cropping systems such as the coffee- and coconut-based cropping systems and the presence of other farming systems and of multiple agro-forestry farms in Cavite. One of the most popular cropping systems is the coffee-based cropping system because the climatic and soil conditions in Cavite are favourable in the production of coffee as the base crop and other intercrops. This is one of the major reasons why the province has been successfully producing coffee. The major coffee-producing municipalities in Cavite include Alfonso, Amadeo, and Silang.

The primary intercrops in the coffee-based cropping systems include annual upland crops that are grown in upland areas and mature in less than one year. The life cycle of these crops is completed in less than a year and the plants die soon after the fruits have been matured and harvested. The upland areas of Cavite are natural habitats of most of these annual crops and there is a wide diversity of species belonging to this group of plants suited for the locality. They are classified according to their morphology and cultural requirements as: (1) grain crops; (2) vegetables; (3) root crops; (4) field crops; and (5) non-food crops.

With the wide variety of annual upland crops, cropping patterns in upland Cavite are more numerous than those in the lowland. These cropping patterns are classified into: those with fast-maturing annuals and those with slow-maturing annuals. Other intercrops include perennial crops or those plants with life cycle that spans over a period of more than a year and that the vegetative growth lasts for many years. Some of the common perennial intercrops in the province are coconut, banana, papaya, mangoes and other fruit trees, pineapple, cacao, black pepper, and a lot of other species.

Multiple cropping with perennial upland crops has several advantages. Firstly, the maintenance of an established plantation is easy and inexpensive; secondly, given the long vegetative stage of most perennial crops and the wide spacing of planting used for many crops, fast-maturing annuals can be intercropped. These intercrops would then serve as cover crops that will help in reducing soil erosion.

\section{Statement of the Problem}

While coffee-based farms in Cavite continue to exhibit high levels of productivity and profitability, the government, development planners, and other stakeholders are beginning to realize that it is also important to assess the farms in terms of the overall systems sustainability considering that coffee trees in the province of Cavite are relatively much older than the other coffee-based cropping systems in the country. Moreover, the commodity is facing market and price risks as a result of competition from other producers in the country and 
the entry of imported coffee, which in the future may result to declining production and profit. Alternative cropping patterns and agricultural production enterprises may also lure coffee farmers to shift to these other farming systems, thus putting the entire coffee industry in the province in the brink of collapse.

The study tried to ascertain if there are significant differences in the levels of sustainability of coffee-based farms across the three municipalities representing the three types of cropping systems in terms of:

(1) Economic dimensions such as input productivity, system profitability, and foreign exchange/value-added potential of farm produce;

(2) Social dimensions such as more job opportunities, better food security, and ability to generate institutional support from government and private sector;

(3) Technological dimensions such as technical support, material input use, and management intervention contributing to the improvement of systems performance;

(4) The environmental dimensions such as impact on soil quality, prevention of soil erosion, and provision of infrastructures contributing to the improvement of systems performance;

(5) The overall systems sustainability (all dimensions considered).

\section{Scope and Limitations}

The study areas include the municipalities of Alfonso, Amadeo, and Silang where coffee and its intercrops are widely cultivated covering the cropping year 2014. It should be noted, however, that the multiple crop farms were not established in the same cropping season—some farms have been in operation long before the establishment of the other farms. These things may have some effects on system performance particularly sustainability.

The data gathered were aggregated to represent the system performance of the coffee-based multiple farming technique in terms of the three dimensions perceived to have effects on the overall system sustainability such as the economic, social, and environmental factors. Indicators under each dimension are arbitrarily chosen from the possible list of factors that may contribute to sustainability. There may be other more important factors that can better measure sustainability that the study failed to consider.

The scoring system used in the study may not be the most efficient approach in assigning weights to preselected factors in each dimension. While the social and environmental factors may have greater impact or contribution on the systems sustainability, economic dimension is given more consideration in this study. The crops included in the analysis are those which are widely cultivated in upland Cavite and those which are practiced during the survey period. These include, but are not limited to coffee, pineapple, papaya, black pepper, fruit trees, vegetables and root crops, and non-food crops. Other crops considered to be irregular intercrops for coffee-based farms will not be included.

\section{Review of Related Literatures}

This section presents some of the related literatures and findings of previous studies which served as the basis in the conduct of this study. This part also includes some insights about the multiple cropping systems in the Philippines and other countries in the tropics and issues related to the sustainability of agricultural production systems.

Price, Gonzaga, and Acebedo (1984), in their study, asserted that a specific cropping system is often described by the dominant cropping pattern it includes. A cropping pattern represents the spatial and temporal 
combination of crops on a plot in such a way that, at all times, during a year, plants of each cultivar at the same stage of growth are uniformly spaced throughout the plot. The profitability and productivity of a cropping pattern are related to the effectiveness or resource use in a pattern and output response. Sajise and Ganapin Jr. (1990), however, mentioned in their report in 1990 that the role of upland development cannot solely be measured in terms of increased productivity of income. Because of the fragile nature of the uplands, stability and sustainability need to be taken into account. They added that stability as a goal for upland development is not difficult to assess. It presents the ability of the system to recover from minor and regular occurring stresses.

The study of Espino and Atienza (2001), documented that successful diversification practices in the Philippines in the late 1980's did not include coffee-based farming systems. The creation of the National Committee on Crop Diversification (NCCD) in 1992 resulted in the preparation and implementation of four commodity-based plans for rice, corn, coconut, and sugarcane. With the enactment of the Agriculture and Fisheries Modernization Act in 1997, other crops were considered and there was an increase in public expenditure on R\&D. One of the components of the Modernization Act is the Philippine Agenda for Research and Development where crop diversification is a major component. Realizing the potential of coffee and cacao, these crops were included in the major commodity thrusts of the government.

Cuthbertson (2013) in his study on the delivery of extension services in the Philippines claimed that public delivery of such services has largely devolved to provinces, cities, municipalities, and villages as a result of the 1991 Devolution, a production system of Powers Act. Thus, answers to questions of the relative roles of private and public extension services and the financing and delivery of public extension are important.

According to Hoang (1999), the productivity of any agricultural systems is important in efficiently providing foods and other products needed by people. Productivity is important in farming system management. However, with the development of sustainable agricultural concepts, there is a growing concern to find a trade-off between the productivity and ecological soundness of agriculture. So far, agricultural systems with high productivity generally tend to exploit natural resources causing natural resource degradation affecting sustainability.

Fisher (1990) suggested that the model of system should be looked at for its ability to provide sustained yield over time to produce immediate returns or benefits and to continue to produce over the medium- and long-term. He mentioned this in his research in 1990 and added that an emphasis should be placed on stable systems adaptable to the local environment that are not easily threatened by sudden changes in socio-economic and environmental factors and that the systems should address conservation aspects.

Ton (2013) claimed that productivity is very location-specific and dependent on factors such as soil quality, water availability, mono or mixed cropping, plant density, etc. For proper comparative research, it is essential to have a good context description of a particular system and the reference systems. He added that it is important also to look at profitability because a production system may be very productive but may be marginal in terms of profitability. Conversely, a production system may be profitable while not being particularly productive because profitability is particularly dependent on sale price per unit and on the costs of production.

\section{Conceptual Framework}

Weidner et al. (2011) in their study made use of the Model for Assessing the Sustainability of Agroforestry Systems (MASAS) which is based on quantitative and qualitative indicators that are measured for every agroforestry parcel examined. According to the study, the achievement of sustainable development 
requires the integration of its economic, environmental, and social components at all levels. The dimensions of sustainability, therefore, include: (1) economic dimension - generation of sufficient income; (2) environmental dimension — preserving the natural resources; and (3) social dimension — socially viable. This study served as the basis of the framework shown in Figure 1. It is based on the concept of sustainability which refers to the capacity of the coffee-based cropping systems to maintain its characteristics and performance in terms of the four major dimensions such as economic, social, technological, and environmental aspects. The existing coffee-based farms in Cavite are assumed to be independent farm units affected by external factors which serve as opportunities as well as threats to the systems. These external facrors may either provide opportunities for the cropping systems thereby improving the performance of the system or post as threats or challenges to the coffee-based farms and serve as hurdles in further improving the coffee-based systems and hampering the sustainability of the farms.

\section{Opportunities \\ (1) Technical breakthroughs \\ (2) Changes in demand pattern \\ (3) Changes in government policy/priorities \\ (4) Development of infrastructure \\ (5) Development of new trade arrangements}

\section{Challenges/threats}

(1) Market risks

(2) Price risks

(3) Risks associated with existing cropping system/benefits associated with new cropping systems

(4) Socio-economic needs (employment, food security, and management complexity)

(5) Adverse changes/degradation of natural resources and environment

\section{Economic}

(1) Resource productivity

(land, labour, fertilizer, and capital)

(2) Cropping system profitability

(3) Foreign exchange/value-added potential

Social

(1) Job opportunity

(2) Food security

(3) Institutional support/subsidy

Environmental

(1) Impact on soil quality

(2) Soil erosion prevention

(3) Climate change mitigation

\section{External factors}

System dimensions

Figure 1. Conceptual framework in the analysis of coffee-based farming systems in upland Cavite.

Economic dimensions include economic performance such as input/resource productivity, system profitability, and the foreign exchange earning/value-adding potential of crops grown in the cropping systems. These systems' characteristics and performance are perceived to contribute to the economy by way of generating revenue and creating market for factors of production such as land, labour, fertilizer, and capital. Social dimensions include the systems contribution in creating job opportunities and absorbing the available farm labour, the production of a wide range of products (crops) to the market contributing to food security, and the opportunity of other crops to be included in the commodity thrusts of the government and private sectors for possible support. The technological dimensions include technical support in the areas of production, marketing and finance, the material input use such as fertilizers and chemicals, and the management interventions in the form of trainings and seminars provided by various stakeholders to the coffee farmers. Figure 1 shows the 
framework to be used in analysing the various coffee-based cropping systems in the three municipalities representing the three types of coffee-based cropping systems in upland Cavite.

\section{Research Methodology}

\section{Research Design}

The study made use of the scoring system or scaling and the scores were generated through the Model in Assessing the Sustainability of Coffee-Based Systems (MASCBS). The model is a combination of quantitative and qualitative contributions or effects of the various dimensions contributing to sustainability such as the economic, social, technological, and environmental factors on individual system. Two groups of respondents were taken as samples - the coffee-based farmers in the three selected municipalities such as Alfonso, Amadeo, and Silang and a group of experts comprising of farmers, agricultural economists and engineers, and agriculturists or agricultural technicians. A comparative analysis with the use of the analysis of variance was employed to ascertain if there are significant differences in the sustainability indices across the three types of cropping patterns considering all the dimensions perceived as contributory or affecting the sustainability of the systems.

\section{Population, Sampling Procedure, and Data Gathering}

The towns of upland Cavite, namely Alfonso, Amadeo, and Silang were preselected as the study areas (see Figure 2). These towns were considered on the basis of the volume of coffee production and the extent of adaption of the coffee-based cropping techniques as evidenced by the historical production data from the Office of the Provincial Agriculturist. Sixty sample-farmers (20 from each municipality) were selected from the roster of coffee-based cropping systems in the province. A group of experts composed of progressive coffee farmers, agricultural economists, agricultural engineers, agriculturists, and agricultural technicians from the province of

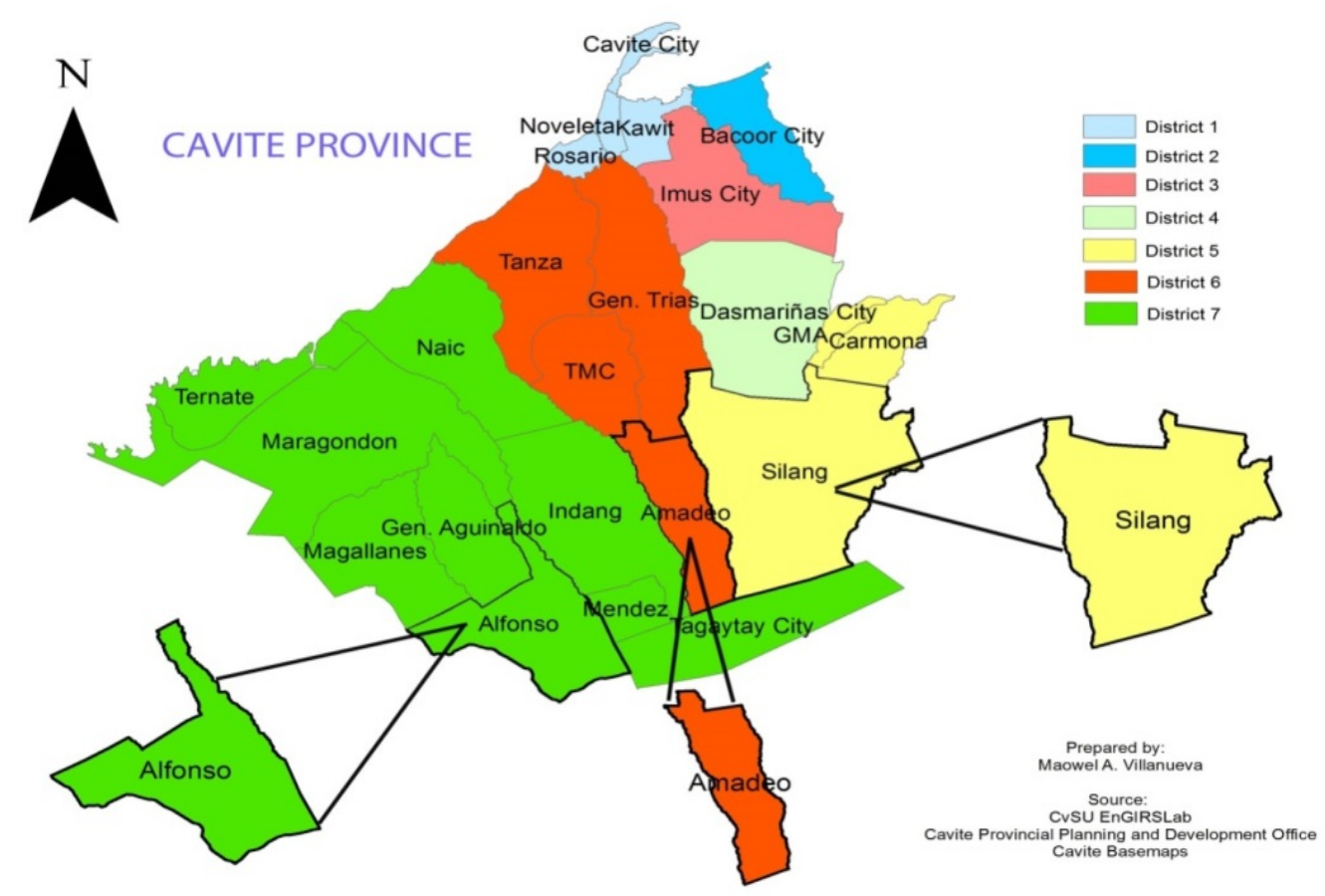

Figure 2. Map of Cavite showing the three municipalities of Alfonso, Amadeo, and Silang which served as the study areas. 
Cavite were invited for a meeting to discuss relevant issues and identify major factors contributing to and affecting the development of the coffee-based cropping systems in Cavite and to determine the important dimensions and factors contributing to or affecting the systems sustainability. Their expert opinions were noted and served as one of the bases in the analysis of the systems.

\section{Data Analysis and Statistical Treatments}

Dimension scaling and ranking. Scaling and ranking were employed as an approach and methodology because many indicators could be measured through quantitative data while some indicators had to be established based on qualitative descriptors. Ranking allowed both quantitative and qualitative data to be side by side in one analytic system. Each dimension was first rated by 20 experts composed of coffee farmers, agricultural economists, agricultural engineers, and agriculturists or agricultural technicians using the indicator, and was measured using the following scale representing the extent of contribution to or effect on sustainability as perceived by the experts. The average scale was then computed by dividing the total scale assigned by experts and divided by 20 and subsequently the dimensions were ranked from highest to lowest with the highest average scale being the first or most important dimension contributing to or affecting the system sustainability. The scale is given as:

$\begin{array}{lc}\text { Qualitative description } & \text { Scale } \\ \text { Highly contributory } & 3 \\ \text { Contributory } & 2 \\ \text { Moderately contributory } & 1\end{array}$

Factor weighting. The selection of indicators representing the four dimensions of sustainability alone was not sufficient to approximate the level of sustainability of a specific system. Some indicators were considered more important than others. Therefore, in using the MASCBS approach, not every indicator carried the same weight. Reflecting its importance, an indicator could contribute to MASCBS with a weight of 1, 2, or 3. The weighting procedure was developed in consultation with experts. The following weights served as basis:

\section{Qualitative description (Opportunities)}

Highly contributory

Contributory

Less contributory
Factor weight 3
Qualitative description (Challenges/threats)
Less damaging
Damaging
Highly damaging

Indicator scaling. Sustainability indicators identified were classified into high, medium, and low using the following scale in order to assess the performance of the coffee-based farms across municipalities. The values of the indicators were generated through interviews of farmers using the prepared interview schedule. The three-point factor scale was used (high $=3$, medium $=2$, low $=1$ ) for all the indicators. Economic indicators included input productivity (land, labour, and fertilizer), system profitability, and foreign exchange earnings and value added potential of the systems. Social indicators included job opportunity, food security, and government commodity-based projects. Technical indicators comprised the technical support on functional areas of management, material input used, and management intervention. Finally, environmental indicators included perceived contributions of systems to soil quality improvement, soil erosion prevention, and physical infrastructure development. 
MASCBCS scoring. In order to assess the sustainability of the different coffee-based cropping systems across municipalities, the model used in the study by Weidner et al. (2011) which is called the MASAS will be adopted with modifications. MASAS is based on quantitative and qualitative indicators that are measured for each agroforestry parcel examined. In this study, the MASAS is modified into Model for Assessing the Sustainability of Coffee-Based Cropping Systems (MASCBCS). Only three dimensions are considered in this study. These include: (1) economic; (2) social; and (3) environmental dimensions. A new dimension is introduced in the model by adding the fourth dimension - the technological dimension. The sustainability dimensions are operationalized by identifying specific indicators of each dimension. The resulting data are then put into a scoring table called the MASCBCS scoring table, to compute the individual systems against each other, and to assess their sustainability. The resulting numeric score will be called the MASCBCS score. The higher the MASCBCS score is, the more sustainable a coffee-based cropping system is.

Comparative analysis. Another research design used in the study is the comparative method of research with the aid of analysis of variance (ANOVA). The ANOVA will be used to compare the economic indicators (total value of outputs, productivity of variable inputs/resources, and levels of profit and profitability) and the overall system sustainability (MASCBCS scores) across the three municipalities representing varying types of coffee-based intercropping systems. MASCBS scores in terms of the specific dimensions and the overall system sustainability (all systems considered) shall be compared and the existence of significant difference will be ascertained.

\section{Results and Discussions}

As perceived by the experts, economic dimension is the most important external contributor to sustainability of coffee-based cropping systems and new trade arrangements and technological breakthroughs are the most important factors that serve as opportunities to the systems. Indicators under the economic and environmental factors are considered by experts to post the greatest threat to the overall system sustainability of coffee-based farms. Table 1 presents the factor ratings of the various indicators contributing to sustainability (opportunities) and those affecting the system performance (threats) based on the responses of the expert subjects.

The three types of coffee-based cropping system represented by the three municipalities were assessed based on the economic performance, social contribution, levels of technology adoption or utilization, and support to environmental preservation. Economic indicators considered in the evaluation include the average value product of the inputs and the presence of commercial and industrial crops in the systems with foreign exchange earnings potential and value-added potential. Social indicators identified include the job opportunity created and hired by the systems, the presence of food crops, and the presence of crops considered by government and private institutions within their priority programs or thrusts. Technological indicators include the nature of technical support availed by farmers, the material input utilization (inorganic fertilizer), and management interventions through trainings and seminars provided to the farmers. Lastly, environmental indicators comprise of presence of crops that can help improve soil quality (fertility and water storage capacity), presence of deep-rooted fruit trees preventing soil erosion, and the different physical infrastructure surrounding the coffee-based farms designed to directly or indirectly increase farm productivity and income. 
Table 1

Average Rating (Scale) of the Various Indicators Contributing to Sustainability of Coffee-Based Cropping in Terms of Specific Performance Indicators

\begin{tabular}{|c|c|c|c|}
\hline \multirow{2}{*}{ Indicator } & \multicolumn{3}{|c|}{ Average weight ${ }^{*}$} \\
\hline & Alfonso & Amadeo & Silang \\
\hline \multicolumn{4}{|l|}{ Economic indicators } \\
\hline Average value product of land & 1.900 & 1.900 & 2.000 \\
\hline Average value product of labour & 1.600 & 1.500 & 1.650 \\
\hline Average value product of fertilizer & 1.100 & 1.150 & 1.150 \\
\hline Return on operating capital & 2.850 & 2.950 & 3.000 \\
\hline Foreign exchange/value added potential & 1.150 & 1.000 & 1.700 \\
\hline \multicolumn{4}{|l|}{ Social indicators } \\
\hline Job opportunity & 1.400 & 1.250 & 1.150 \\
\hline Food security & 1.750 & 1.450 & 1.650 \\
\hline Government policy/priority & 1.250 & 1.050 & 1.700 \\
\hline \multicolumn{4}{|l|}{ Technological indicators } \\
\hline Technical support & 1.550 & 1.600 & 1.750 \\
\hline Material input utilization & 2.300 & 1.400 & 1.750 \\
\hline Management intervention & 1.150 & 1.400 & 1.250 \\
\hline \multicolumn{4}{|l|}{ Environmental indicators } \\
\hline Soil quality improvement & 1.050 & 1.000 & 1.000 \\
\hline Soil erosion prevention & 1.000 & 1.050 & 1.050 \\
\hline Infrastructure development & 1.300 & 1.150 & 1.250 \\
\hline
\end{tabular}

Table 2 shows the average rating (scale) of the various indicators contributing to sustainability. Silang farms exhibited the highest scale or rating in all the economic indicators. Among the economic indicators, return on operating capital had the highest rating signifying that this economic factor was highly contributory to system sustainability for all the cropping systems. Alfonso farms had the highest rating in two of the social indicators considered. In terms of the social dimension, Alfonso farms seemed to have the highest rating as reflected by the highest sustainability indices for job opportunity and food security while Silang exhibited the highest index on government policy and priority. Taking into consideration the technological factors, Silang farms showed the highest index for technical support while Alfonso farms' sustainability index was highest for material input utilization. Amadeo farm' sustainability score was highest in terms of the management intervention by government and private institutions. In terms of the environmental dimension, the three types of systems were relatively at par with each other.

Previous study (Cubillo, 2016) revealed that all the cropping systems were more or less efficient in terms of production, productivity and they were profitable. Among the three cropping systems, however, it was the cropping system 3 (Silang - intercropping coffee with industrial and commercial crops) which appeared to be the most efficient and profitable, considering the productivity of all the resources/inputs such as land, labour, and fertilizer and the degree of system profitability. Silang farms also registered to have the highest sustainability index for economic and social dimensions. Cropping pattern 3 (intercropping coffee with industrial and commercial crops) would appear to be the best cropping system and worth recommending to interested farmers since intercropping coffee with industrial or commercial crops would generate more income 
for the farmers as most of these intercrops produced the highest value per unit of resource or input used to produce them.

Table 2

Average Rating (Scale) of the Various Indicators Contributing to Sustainability of Coffee-Based Cropping Systems in Terms of Specific Performance Indicators

\begin{tabular}{ll}
\hline Indicator & Average weight $^{*}$ \\
\hline Economic indicators & 1.933 \\
\hline Average value product of land & 1.583 \\
Average value product of labour & 1.133 \\
Average value product of fertilizer & 2.933 \\
Return on operating capital & 1.283 \\
Foreign exchange/value added potential & \\
\hline Social indicators & 1.267 \\
\hline Job opportunity & 1.617 \\
Food security & 1.333 \\
Government policy/priority & \\
\hline Technological indicators & 1.633 \\
\hline Technical support & 1.817 \\
Material input utilization & 1.267 \\
Management intervention & \\
\hline Environmental indicators & 1.017 \\
\hline Soil quality improvement & 1.033 \\
Soil erosion prevention & 1.233 \\
Infrastructure development & \\
\hline Notes. Weight 3 & \\
\hline
\end{tabular}

Notes. Weights ${ }^{*}$ 3-Highly important (opportunity)/less destructive (threat); 2-Important (opportunity)/destructive (threat); 1 - Less important (opportunity)/less destructive (threat).

Table 3

Differences in the Average MASCBS Scores of the Different Cropping Systems Grouped by Municipality

\begin{tabular}{lcccc}
\hline \multicolumn{5}{c}{ Average MASCBS score } \\
\hline Dimension & Alfonso & Amadeo & Silang & $F$ value \\
\hline Economic & (Pattern 1) & (Pattern 2) & (Pattern 3) & $4.205^{*}$ \\
Social & 1.433 & 1.417 & 1.583 & $2.189^{\text {ns }}$ \\
Technological & 0.880 & 0.750 & 0.900 & $1.490^{\text {ns }}$ \\
Environmental & 1.000 & 0.880 & 0.950 & $0.573^{\text {ns }}$ \\
All dimensions & 0.838 & 0.800 & 0.825 & $3.813^{*}$ \\
\hline
\end{tabular}

Notes. ${ }^{*}$ Significant at $5 \%$ level of $\alpha$; ns $=$ not significant at $5 \%$ level of $\alpha$.

In terms of the overall system sustainability with the four major dimensions considered, however, the cropping systems differed as shown in Table 3. The MASCBS score for each farm was computed. The score was the value representing the level of sustainability of each coffee-based farm equivalent to the dimension weight (\%) multiplied by the aggregate factor weights. The higher MASCBS score meant the higher level of sustainability of a particular farm or group of farms.

Coffee-based cropping systems sustainability (index) as influenced by economic factors differed significantly across system patterns or municipalities with cropping pattern 3 (Silang) having the highest. 
Sustainability indices as influenced by social factors, by technological factors, and by environmental factors did not differ significantly across cropping patterns. However, the overall system sustainability (index) considering all the dimensions differed significantly across municipalities suggesting that, indeed, it was the economic dimension that had the greatest influence on sustainability.

Cropping system 1 (Alfonso farms - intercropping coffee with industrial/commercial crops, fruit trees, and food crops) had the highest sustainability index for technological and environmental dimensions. Combining the good traits of cropping system 1 (Alfonso) and cropping system 3 (Silang), would be a better recommendation. More productive, profitable, and sustainable cropping system may be realized. These good traits of the two cropping systems would include expanding farm size, intercropping with additional crops such as fruit-bearing trees and some food crops which are positive attributes of Alfonso cropping system and maintaining efficient use of resources and inputs which is the good characteristic of cropping systems in Silang.

\section{Conclusions and Recommendations}

On the basis of the empirical evidence and the results of the analysis of the data, economic factors seemed to be the primary contributor (opportunity) to the overall system sustainability and the same economic factors are the major threats that may affect the system performance. While most of the sustainability indices in all the dimensions were different across cropping patterns, the differences were not statistically significant for social, technological, and environmental factors. Differences are significant only for the economic dimension suggesting that economic factors are the most important factors that contribute to or affect the system sustainability. These results were consistent with the claims of the majority of the experts who supported the claim that the relative importance of economic factors/dimension is shaping the sustainability of the coffee-based cropping systems in general.

With these conclusions, stakeholders must provide avenues and opportunities to coffee-based farmers for possible new trade arrangement with local processors and exporters for coffee and its intercrops to add more value on the produce. Prices of output or produce must somehow be protected to give positive signals to farmers and to ensure that their investments and expenditures in their farms may generate more income for them to sustain the management and operation of their farms or expand their production or even diversify through processing their produce.

Adjustments in cropping calendars and patterns and changing management and farming practices may be considered to improve sustainability including integrating water efficient crops, crops contributing to soil fertility and preventing soil erosion. Moreover, more intercrops and crop rotation may be adopted to provide a wider variety of products especially high-value crops both for final consumption and processing. Application of technologies designed to further increase productivity is highly recommended. Lastly, appropriate economic incentives such as market opportunities subsidies and price support to farmers and tax incentives to enterprises and industries linked to coffee-based farm products post production systems such as processing and the whole food supply chain would greatly ensure the sustainability of the coffee-based cropping systems.

\section{References}

Adriano, M. S., \& Cabezon, V. E. (1993). Economic policies affecting crop diversification in the Philippines. Proceedings from National Workshop on Crop Diversification in the Philippines. IIMI, Sri Lanka.

Arizala, L., \& Gonsalves, J. (1990). Multistoried cropping system: A farmer derived agroforestry system. Resource book on sustainable agriculture for the uplands. International Institute for Rural Reconstruction (IIRR), Philippines. 
Cubillo, G. P. (2016). Resources productivity and systems sustainability of selected coffee-based farms in upland Cavite, Philippines. Journal of US-China Public Administration, 13(5), 322-332. David Publishing, USA, May 2016.

Cuthbertson, S. (2013). Improving delivery of extension services in the Philippines. Australian Centre for International Agricultural Research.

Espino, R. R. C., \& Atienza, C. S. (2001). Crop diversification in the Philippines. In M. K. Papademetriou and F. Dent (Eds.), Crop diversification in the Asia-Pacific region. FAO Regional Office for Asia and the Pacific, Bangkok, Thailand, April 2011.

Fisher, L. A. (1990). Developing small-scale afforestation: Guidelines for farmers and facilitators. Resource book on sustainable agriculture for the uplands. International Institute for Rural Reconstruction (IIRR), Philippines, July 1990.

Hoang, V. P. (1999). Farming systems analysis of farm-households at Dinhhoa District, the Northern Uplands of Vietnam. Unpublished doctoral dissertation, University of the Philippines, Laguna, February 1999.

Price, E. C., Gonzaga, R., \& Acebedo, V. (1984). Testing cropping pattern for economic criteria.

Sajise, P., \& Ganapin Jr., P. (1990). Overview of upland farming issues. Resource book on sustainable agriculture for the uplands. International Institute for Rural Reconstruction (IIRR), Philippines.

Ton, P. (2013). Productivity and profitability of organic farming systems in East Africa. IFOAM, Bonn, Germany.

Weidner, S., Bünner, N., Casillano, Z. L., Sales-Come, R., Erhardt, J., Frommberg, P., Peuser, F., \& Ringhof, E. (2011). Towards sustainable land-use: A socio-economic and environmental appraisal of agroforestry systems in the Philippine uplands. SLE Publication Series-S246, Humboldt-Universitat Zu Berlin, December 2011. 